\title{
MI 1,11.14d-f: alguns aspectos teológicos da justificativa da crítica do profeta Malaquias ao culto do Segundo Templo
}

\author{
MI 1,11.14d-f: \\ some aspects of the theological justification \\ of the criticism of the prophet Malachi \\ to the Second Temple Worship
}

Fábio da Silveira Siqueira

\section{Resumo}

O texto de Ml 1,11.14d-f pertence à perícope de Ml 1,6-14, onde o profeta apresenta a sua crítica ao culto do Segundo Templo. A crítica se centraliza em dois aspectos: a oferta de vítimas inapropriadas (cf. Ml 1,7.8.13e) e uma atitude de desprezo com relação ao culto (cf. Ml 1,13b.13c). Esta comunicação tratará especificamente dos vv. 11 e 14d-f onde o profeta justifica teologicamente a sua crítica, apresentando YHWH como um "grande Rei", cujo "nome" é "terrível entre as nações". A presente comunicação visa apresentar resumidamente o sentido da crítica profética e, particularmente, deter-se sobre dois aspectos teológicos subjacentes aos vv. 11 e 14d-f, quais sejam a teologia do "nome" de YHWH e a imagem de YHWH como "grande rei". Esta comunicação chega à conclusão de que, o sentido de M1 1,11 só pode ser plenamente compreendido quando este versículo é lido em conjunto com Ml 1,14d-f e, à luz dos aspectos teológicos ressaltados acima.

Palavras-chave: Teologia Bíblica; Segundo Templo; Profetismo; Livro de Malaquias. 


\begin{abstract}
The text of Ml 1,11.14d-f belongs to the pericope of Ml 1,6-14, where the prophet presents his critique of the Second Temple's cult. The prophetic critique centers on two aspects: the inappropriate victims to the sacrifice (cf. Ml 1,7.8.13e) and an attitude of contempt towards the cult (cf. Ml 1,13b.13c). This communication will deal specifically with vv. 11 and 14d-f where the prophet theologically justify his critique, presenting YHWH as a "great king", whose "name" is "terrible among the nations." This communication wants to present briefly the meaning of prophetic critique and dwell especially in two theological aspects of the vv. 11 and 14d-f, which are the theology of the "name" of YHWH and YHWH's image as "great king". This communication comes to the conclusion that the sense of Ml 1,11 can only be fully understood when this verse is read in conjunction with $\mathrm{Ml} 1,14 \mathrm{~d}-\mathrm{f}$, and in the light of the theological aspects highlighted above.
\end{abstract}

Keywords: Biblical Theology; Second Temple; Profetism; Book of Malachi.

\title{
1. Introdução
}

O objetivo desta comunicação é abordar alguns aspectos teológicos atinentes à crítica do profeta Malaquias ao culto do Segundo Templo. Para alcançar este objetivo esta comunicação está dividida em duas partes: primeiro é apresentada sumariamente a crítica do profeta ao culto do Segundo Templo presente na perícope de Ml 1,6-14 e, brevemente, a história da interpretação do v. 11, ponto crítico da justificativa da crítica profética; em segundo lugar, serão apresentados dois aspectos teológicos importantes para se entender a crítica do profeta ao culto do Segundo Templo.

\section{A Crítica do Culto em Malaquias}

$\mathrm{O}$ texto de Ml 1,11.14d-f pertence à perícope de Ml 1,6-14, onde o profeta apresenta a sua crítica ao culto do Segundo Templo. A crítica se centraliza em dois aspectos: a oferta de vítimas inapropriadas (cf. Ml 1,7.8.13e) e uma atitude de desprezo com relação ao culto (cf. Ml 1,13b.13c). O texto, dividido em duas seções, chega a seu ápice em cada uma de suas partes com a justificativa da crítica do profeta ao culto do Segundo Templo: 
Porque, do nascente do sol até o seu ocaso grande é meu nome entre as nações,

e em todo lugar incenso é oferecido ao

meu nome e uma oferta pura;

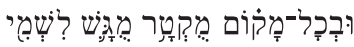

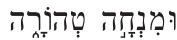

porque, grande é meu nome entre as nações, diz YHWH dos Exércitos.

$11 \mathrm{c}$

$11 \mathrm{~d}$

$14 d$

$14 \mathrm{e}$

diz YHWH dos Exércitos,

e meu nome é terrível ${ }^{1}$ entre as nações.

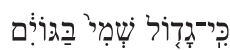

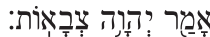

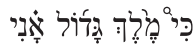

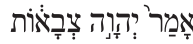

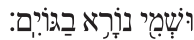

O v. 11 e o v. 14d-f trazem o que se pode chamar de "a justificativa da crítica" do profeta Malaquias ao culto do Segundo Templo. O v. 11 apresenta uma dificuldade na história de sua interpretação: trata-se de um conjunto de orações nominais cuja temporalidade deve ser determinada pelo contexto. Dependendo do tempo pelo qual se traduz esse versículo a sua interpretação pode ser também diversa. Na história da interpretação do referido versículo encontramos as seguintes possibilidades:

a. Ml 1,11 como uma predição do sacrifício eucarístico (Didaché; Justino; Irineu de Lião; Anáfora de São Marcos)²;

b. Ml 1,11 como se referindo aos judeus da diáspora:

b.1. Culto em outros templos fora de Jerusalém (Michael Floyd);

b.2. Espiritualização do culto: frequência nas sinagogas da Diáspora (Targum; Swetnam ${ }^{4}$ );

b.3. Culto dos prosélitos (Verhoef) ${ }^{5}$;

${ }^{1}$ Cf. STÄHLI, H. P. ירא. In: DTMAT I, pp. 1055-1056.

${ }^{2}$ Cf. Didaché 14,3. In: Padres Apostólicos. São Paulo: Paulus, 1995, pp. 357-358; Diálogo com Trifão 117, 2.4. In: Justino Mártir. I e II Apologias e Diálogo com Trifão. São Paulo: Paulus, 1995, pp. 287-289; Adversus Haereses IV, 1.5. In: Ireneu de Lião. Contra as Heresias. São Paulo: Paulus, 1995, pp. 414.419; STEVENSON, K. Liturgy, Use of the Bible in. In: COGGINS, R. J.; HOULDEN, J. L. A Dictionary of Biblical Interpretation. London: SCM Press. 1990. pp. 405-406.

${ }^{3}$ Cf. FLOYD, M. Minor Prophets: Part 2. Grand Rapids, Michigan. Eerdmans. 2000. p. 595.

${ }^{4}$ Cf. CATHCART, K. J.; GORDON, R. P. The Targum of the Minor Prophets. Collegeville, Minnesota: Liturgical Press. 1990. pp. 230-1 e nota 26; SWETNAM, J. Malachi 1,11: An Interpretation. Catholic Biblical Quaterly 31. 1969. p. 207.

${ }^{5}$ Cf. VERHOEF, P. The Books of Haggai and Malachi. Grand Rapids, MI: Eerdmans. 1987. pp. 230. 


\author{
c. $\quad$ Ml 1,11 como texto escatológico (Achtemeier) ${ }^{6}$; \\ d. Ml 1,11 como referência ao culto pagão (Lescow; Lindblom; Dentan; \\ Teodoro de Mopsuéstia; Clemente de Alexandria) ${ }^{7}$; \\ e. Ml 1,11 como uma metáfora (Åke Viberg) $)^{8}$; \\ f. A interpretação teológica (Mason; Vriezen; Kessler; Meinhold) 9 .
}

Sem entrar em maiores detalhes de gramática hebraica, parece mais verossímil a tradução do v.11 pelo presente, uma vez que, no contexto da perícope, nada há que aponte para uma possível tradução pelo futuro. Tal tradução seria já fruto de uma interpretação. Acredita-se que o profeta possa estar se referindo ao culto pagão, como afirmaram Teodoro de Mopsuéstia e Clemente de Alexandria, ou seja, não acreditando que este culto, em si, era melhor que o culto judaico, mas utilizando a boa índole dos pagãos que oferecem de boa-vontade suas melhores ofertas aos seus deuses (que nem deuses são, uma vez que Israel já tinha alcançado, neste período, uma plena concepção monoteísta ${ }^{10}$ como paradoxo para a atitude dos sacerdotes e do povo judeu, que oferecem de má vontade o que há de pior para YHWH, o único e verdadeiro Deus.

\footnotetext{
${ }^{6}$ Cf. ACHTEMEIER, E. Naum-Malachi. Kentucky, Louisville: John Knox Press. 1986. pp. 177-181. ${ }^{7}$ Cf. LESCOW, T. Das Buch Maleachi. Stuttgart: Calwer Verlag. 1993. p. 90; LINDBLOM, J. Prophecy in Ancient Israel. Oxford: Blackwell. 1962. p. 406; DENTAN, R. C. The Book of Malachi. In: Interpreter's Bible V. VI. Edited by G. A. Buttrick et allii. 12 volumes. New York: Abingdon Press. 1951-1957. pp. 1128-1129; PG 66, col. 605 citado em CHARY, T. Aggée-Zharie-Malachie. Paris: Gabalda. 1969. p. 243; Clemente de Alexandria. Stromata V. Tomo I. Paris. Éditions Du Cerf. p. 241: "Quant ao prophète Malachie, il fait dire à Dieu expressément: 'Je n'agréerai pas de sacrifice de votre main, car du lever du soleil à son couchant, mon nom est glorifié parmi lês nations, et en tout lieu um sacrifice m'est offert.' Et encore: 'Car je suis um grand roi, dit le Seigneur tout-puissant, et mon nom est célèbre parmi lês nations. 'Quel est ce nom? chez lês croyants, c'est le Fils, qui révèle le Père, chez le Grecs,

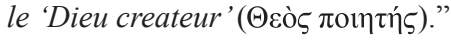

${ }^{8}$ VIBERG, Å. Wakening a Sleeping Metaphor. Tyndale Bulletin. November, 1, 1994. 45(2). pp. 297-319.

${ }^{9}$ Cf. MASON, R. The Books of Haggai, Zechariah and Malachi. London, New York, Melbourne: Cambridge University Press. 1977. pp. 142-145; VRIEZEN, T. C. How to Understand Malachi 1:11. In: COOK, J. [ed.] Grace Upon Grace. Essays in Honor of Lester J. Kuyper. Grand Rapids, Michigan. Eerdmans Publishing Company. pp. 128-136; KESSLER, R. Maleachi. Freiburg Im Bresgau: Verlag Herder. 2011. p. 154; MEINHOLD, A. Maleachi. Düsseldorf: Neukirchner Verlag. 2006. p. 133.

${ }^{10}$ Pode-se datar Malaquias em torno ao ano 450 a.C.
} 


\section{Características teológicas da justificativa da crítica profética}

Olhando a estrutura da perícope percebemos que a mesma se articula em duas partes muito semelhantes, chegando a um mesmo ápice: a proclamação de YHWH como "grande rei" cujo "nome" é "terrível" entre as nações. Assim sendo, podemos destacar dois elementos importantes para entendimento da perícope: primeiro perceber que o v. 11 só pode ser plenamente compreendido, dentro da perícope, quando lido em conjunto com o v. 14d-f; em segundo lugar perceber os aspectos teológicos subjacentes à crítica. Aqui destacamos dois deles: a teologia do "nome de YHWH" e a imagem de "YHWH como Rei".

\subsection{A conexão entre $M l 1,11$ e $M l 1,14 d-f$}

Tanto a estrutura quanto o vocabulário ilustram a conexão entre os vv. 11 e 14d-f. Do ponto de vista da estrutura, como já fora observado mais acima, os dois versículos formam o ápice de cada uma das seções da perícope:

\begin{tabular}{|l|l|}
\hline \multicolumn{2}{|c|}{ Introdução da Perícope (v.6a-e) } \\
\hline Primeira Seção (vv. 6f-11c) & \multicolumn{1}{|c|}{ Segunda Seção (vv.12a-14f) } \\
\hline $\begin{array}{l}\text { Desenvolvimento da crítica } \\
\text { profética (vv. 6f-10) }\end{array}$ & $\begin{array}{l}\text { Desenvolvimento da crítica } \\
\text { profética (vv.12a-14c) }\end{array}$ \\
\hline Justificativa da crítica (v. 11) & Justificativa da crítica (v.14d-f) \\
\hline
\end{tabular}

Do ponto de vista do vocabulário, pode-se destacar a introdução tanto do v.11 quanto do v.14d-f pela preposiçã ’̣̣. Além disto, há uma repetição dos

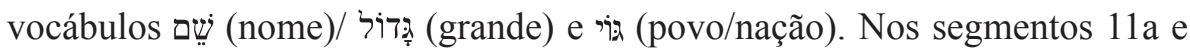

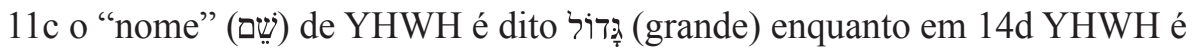

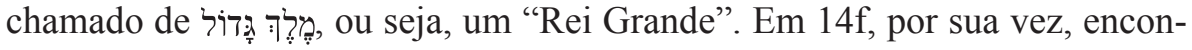
tramos o vocábulo שֶׁ (nome) em conexão com o adjetivo נוֹר (terrível). Tanto no v. 11 quanto no v.14d-f a grandeza do nome de YHWH ou o temor que ele suscita está em referência às "nações" - גּ̇.

Tais similitudes entre os vv. 11 e 14d-f levam a crer que o pleno sentido da perícope e, do próprio v.11, se dá quando os lemos em conjunto e considerando, sobretudo, os aspectos teológicos subjacentes à justificativa da crítica profética. 


\subsection{Ml 1,6-14 e a teologia deuteronomista: \\ o "nome" de YHWH e a importância do Templo (Dt 12)}

O tema do "nome" (שָׁם) de YHWH é recorrente na perícope de Ml 1,6-14. Ele aparece como um elemento de união entre as três partes da mesma perícope. Numa acepção negativa, o termo ocorre na introdução da perícope, no v. 6e, onde são identificados os destinatários da disputa profética. Na primeira seção, ocorre no v. $6 \mathrm{~g}$, na pergunta dos sacerdotes a YHWH após ouvirem o motivo da sua condenação: ter "desprezado o nome" de YHWH. No v. 11, a temática em torno do "nome" de YHWH aparece em sentido positivo nos vv. 11a-c, onde nos vv. 11a e 11c o "nome" de YHWH é dito לił e, e, no v. 11b é afirmado que entre as nações incenso e uma oferenda pura são oferecidos ao seu "nome". Os vv. 11a e 11c emolduram o conjunto do versículo em torno

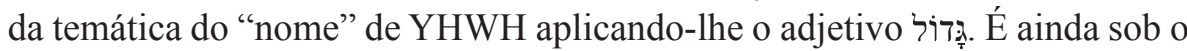
pano de fundo da temática do "nome" de YHWH que a perícope é encerrada no v. 14f, onde agora lhe é aplicado o adjetivo נוֹרָ ".

Segundo Willi-Plein, a temática em torno do "nome" de YHWH é fundamental para o entendimento da perícope e, juntamente com outros termos que nela aparecem, é determinante para marcar a imagem de Deus e a linguagem religiosa do judaísmo posterior e, consequentemente, do Novo Testamento. ${ }^{11}$ Segundo Kessler, a teologia do nome constitui, de fato, como que um elo que une toda a perícope, uma vez que à acusação que YHWH faz aos sacerdotes de terem desprezado (בזה) seu "nome" - a qual eles negam - corresponde agora a grandeza "do nome de YHWH" entre os povos e o temor que seu "nome" desperta entre essas mesmas nações. ${ }^{12}$ Segundo o mesmo autor, Ml 1,11 que traz uma palavra positiva a respeito do "nome" de YHWH, deixa em aberto muitas questões, como por exemplo, quem oferece, onde tais ofertas são feitas, se são oferecidas intencionalmente a YHWH ou se esta é a visão do profeta. Baseado nisso, ele afirma que deveríamos olhar M1 1,11 e, também, toda a perícope de Ml 1,6-14, do ponto de vista da teologia do "nome" de YHWH e da importância do Templo, como habitação do "nome" de YHWH (cf. Dt 12,11). ${ }^{13}$

\footnotetext{
${ }^{11}$ Cf. WILLI-PLEIN, I. Haggai, Sacharja, Maleachi. Zürich: TVZ. 2007. p. 255.

${ }^{12}$ Cf. KESSLER, R. Maleachi. p. 150.

${ }^{13}$ Cf. KESSLER, R. Maleachi. p. 154.
} 
A grandeza universal do "nome de YHWH" se prende a tradições antigas. ${ }^{14}$ No Egito é comum que se encontrem inscrições hieroglíficas onde o nome do Faraó aparece dentro de uma espécie de moldura, para que se possa perceber que se trata da própria presença do Faraó simbolicamente representado em seu nome. Algumas vezes, a moldura com o nome do Faraó é encimada pelo disco solar ou, ainda, acompanhada da imagem de alguém que a reverencia. Todos esses elementos servem para demonstrar que já em épocas antigas o "nome" significava a própria "presença", neste caso, do Faraó. Segundo Kessler, o que aconteceu em Israel foi a transferência de tal ideia para YHWH. Esta mesma tradição a encontramos nos S1 50,1; 113,3.4 e em Is 45,6 e 59,19, às quais, segundo o mesmo autor, remontaria Malaquias. ${ }^{15}$

A temática em torno do "nome" de YHWH nos remete, particularmente, ao texto de Dt 12. O texto evoca a ideia de que há um só "nome" ao qual os israelitas devem adorar e prestar culto. ${ }^{16} \mathrm{O}$ Templo, por sua vez, é a morada do "nome" de YHWH.

No que diz respeito à temática do "nome" de YHWH, poderíamos dividir o texto de Dt 12 em duas partes:

- Dt 12,3: Trata do שֶׁם dos deuses

- Dt 12,5.11.21: Trata do שֶׁ de YHWH

Podem ser notadas semelhanças e diferenças entre Dt 12,2-12.21 e Ml 1,6-14. A primeira e mais notável similitude diz respeito à referência ao "nome" de YHWH. Assim como em Dt 12,5.11.21, o Templo é o lugar onde habita não o próprio YHWH, mas seu "nome". Também em Ml 1,6eg.12a o desprezo dos sacerdotes é em relação ao "nome" de YHWH e em Ml 1,11a-c é ainda o "nome" de YHWH que é "grande", é a seu "nome" que incenso e uma oferenda pura são oferecidos e, por fim, em Ml 1,14f é o seu "nome" que é dito terrível entre as nações. Outra relação significativa encontra-se entre Dt 12,6.7.11 e Ml 1,9a.14. Aqui não se trata de uma simples repetição de vocabulário, mas de palavras que indicam uma certa oposição de comporta-

\footnotetext{
${ }^{14}$ Cf. KESSLER, R. Maleachi. p. 150.

${ }^{15}$ Cf. KESSLER, R. Maleachi. p. 151: "Im Jerusalemer Kult wird die Vorstellung dann auf JHWH übertragen. So heißt es in Ps 133,3: "vom Aufgang der Sonne bis zu ihrem Untergang sei gelobt der Name JHWHs” (vgl. Jes 45,6; 59,19; Ps 50,1). An die Stelle des Pharaos ist JHWH selbst getreten. Auf diese Tradition greift Maleachi zurück."

${ }^{16}$ Cf. CRAIGIE, P. The Book of Deuteronomy. Grand Rapids, Michigan. Eerdmans Publishing. 1976. p. 216.
} 
mento. Em Dt 12,6.11 aparecem termos ligados ao verbo נדר (fazer um voto ou promessa). Segundo Dt 12,6, no Templo devem ser apresentados votos (נָדרָר)

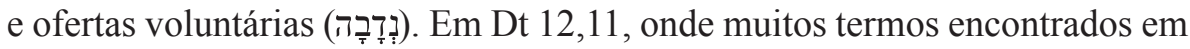
12,6 se repetem, o autor sagrado fala que no Templo devem ser apresentadas

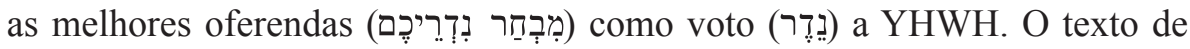
Dt 12,7, por sua vez, fala que o israelita deve comer com alegria diante da face de YHWH (לְפְּני יהוה), aquilo que lhe cabe do sacrifício oferecido como fruto da bênção (ברך) de YHWH. No texto de Ml 1,14, a palavra do profeta se dirige não só aos sacerdotes, mas a todo aquele que, tendo feito um voto (נָרְד), não oferece o "melhor animal" para YHWH, isto é, um זָזָ (animal macho), mas

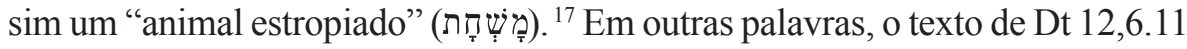
manda oferecer o melhor como voto para YHWH, mas os sacerdotes, em Ml 1,14 oferecem justamente o que há de pior, um

A ligação de Dt 12,7 com Ml 1,14a demonstra-se particularmente através do binômio bênção/maldição (ארר/ברך). Enquanto em Dt 12,7 o israelita deve comer com alegria a parte que lhe corresponde do sacrifício como fruto da bênção (ברך) de YHWH, em Ml 1,14a é dito "maldito" (ארוּר) todo aquele que pretende enganar YHWH oferecendo-lhe um estropiado no lugar de um animal perfeito.

Ainda do ponto de vista das semelhanças destaca-se certa relação entre Dt 12,7 e Ml 1,9a. Em Dt 12,7 se diz que o israelita deve comer com alegria da parte que lhe cabe do sacrifício diante da "face de YHWH" (לְפְנִי יהוה). Em M1 1,9a, por sua vez, o profeta, em tom irônico, convida os sacerdotes a tentarem aplacar a "face de Deus" (פְנְי־אֵ), embora de suas próprias mãos venham oferendas impróprias.

No que diz respeito às diferenças entre Ml 1,6-14 e Dt 12,2-12.21, pode-se destacar, principalmente, a ausência dos termos (incenso) e (oferenda) em Dt 12, os quais são utilizados em Ml 1,11cd para falar do que é apresentado a YHWH pelas nações.

Segundo Weinfeld, é próprio do deuteronomista a teologia do "nome de YHWH". Para este autor, enquanto os círculos sacerdotais beberam de uma teologia de cunho mais antropomórfico, baseados em concepções sacrais mais antigas, a escola deuteronomista se desenvolveu na direção de uma teologia mais abstrata. ${ }^{18}$ Assim, teriam surgido paralelamente duas teologias: a da

\footnotetext{
${ }^{17}$ Cf. GLAZIER-McDONALD. Malachi. Atlanta, Georgia: Scholar Press. 1987. p. 63.

${ }^{18}$ Cf. WEINFELD, M. Deuteronomy and the Deuteronomic School. Winona Lake, Indiana. Eisenbrauns. 1992. pp. 192-193.
} 
"glória de YHWH" (פָּרוֹד יהוה), mais antropomórfica e própria dos círculos sacerdotais, e a do "nome de YHWH" (שָׁם יהוה), mais abstrata e própria do Deuteronômio e da escola deuteronomista. ${ }^{19}$

Para Weinfeld, a mais definitiva expressão da teologia do "nome" de YHWH se encontra em 1Rs 8, particularmente nos vv.22-29, onde se afirma que os "céus dos céus" não podem conter YHWH, muito menos o Templo (cf. 1 Rs 8 ,27). O Templo é o lugar onde YHWH prometeu colocar o seu "nome" e onde as preces dos fiéis serão ouvidas (cf. 1Rs 8,29). ${ }^{20} \mathrm{~A}$ ideia do Templo como habitação do "nome de YHWH" seria para se evitar, então, que se pensasse que a própria divindade estava circunscrita ao Templo. ${ }^{21}$

Em síntese, Ml 1,6-14 trata da importância do Templo como morada do "nome de YHWH". Ao apresentar sacrifícios impuros, os sacerdotes não estão honrando o "nome" de YHWH e acabam por profanar o Templo onde YHWH faz habitar o seu "nome". O fruto de tal profanação será o fechamento das portas do santuário e, consequentemente, a privação da presença de $\mathrm{YHWH}$ (cf. Ml 1,10) e, ainda, uma maldição (cf. Ml 1,14) que é mais pormenorizadamente descrita na perícope seguinte (cf. Ml 2,1-9).

\subsection{Ml 1,6-14 e a imagem de YHWH como Rei}

As suas partes de Ml 1,6-14 chegam a um mesmo ápice, com diversos termos comuns: ${ }^{22}$

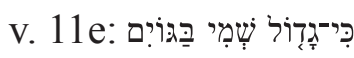
porque grande é meu nome entre as nações

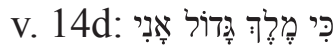
porque eu sou um grande rei

Comparando os vv. 11e e 14d, nota-se que a expressão שִ̣ (meu nome) equivale ao pronome (eu), uma vez que o "nome" de YHWH é Ele mesmo. Seria como se YHWH disesse "Eu sou Grande" e depois repetisse "Eu sou um Grande Rei”. A ausência do artigo definido junto ao substantivo (rei) parece indicar a consciência do profeta de que, na verdade, não existe outro

\footnotetext{
${ }^{19}$ Cf. WEINFELD, M. Deuteronomy and the Deuteronomic School. p. 206.

${ }^{20}$ Cf. WEINFELD, M. Deuteronomy and the Deuteronomic School. p. 195.

${ }^{21}$ Cf. WEINFELD, M. Deuteronomy and the Deuteronomic School. p. 193.

${ }^{22}$ Cf. MASON, R. The Books of Haggai, Zechariah and Malachi. pp. 142-145.
} 
rei senão YHWH mesmo, aquele que governa o mundo. Logo em seguida, em Ml 1,14f, YHWH afirma que seu "nome" é "terrível". Essa sentença vem introduzida por um ı que é colocado logo após a fórmula do mensageiro. Isso indica que, sendo YHWH um "grande rei", as nações "temem" o seu nome.

Assim sendo, parece verossímil afirmar que, paralelo à teologia do nome, é importante dentro da perícope a imagem de YHWH como Rei. Essa leitura parece coadunar-se com Ml 1,8c, onde o profeta convida os sacerdotes a apresentarem tais oferendas defeituosas ao "governador" (פָָָָּ). Ao analisar esse versículo, alguns autores chegam a afirmar que é notório o fato de Malaquias não se remontar a uma tradição escrita ou algo semelhante para criticar os

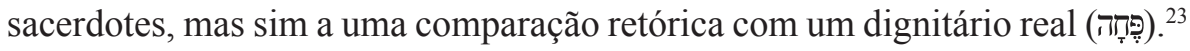

Segundo Willi-Plein o texto do oráculo se desdobra numa "iconografia mental" de um grande cerimonial de corte, onde o culto é compreendido como uma espécie de audiência real, onde se vê a face de Deus, o grande Rei, e se lhe rendem homenagens. Para a mesma autora, a disputa profética, ao atribuir diversos títulos para YHWH, leva o leitor a olhar de um círculo mais interno, familiar, ao chamar Deus de אָ (pai), expandindo depois esse olhar, percebendo assim a grandeza e a santidade do "nome" de YHWH e, depois, ampliando o mesmo olhar até o horizonte, percebendo que YHWH é, também טִּר (um grande rei). ${ }^{24}$

\begin{tabular}{|c|c|c|}
\hline 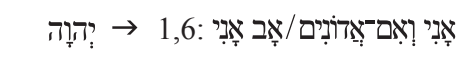 & 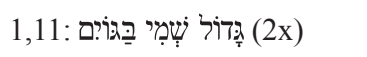 & 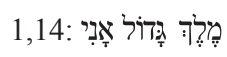 \\
\hline $\begin{aligned} \text { YHWH } \rightarrow & \begin{array}{l}1,6: \text { se eu sou senhor/ se } \\
\text { eu sou pai }\end{array}\end{aligned}$ & $\begin{array}{l}\text { 1,11: o meu nome é } \\
\text { grande entre as nações }(2 \mathrm{x})\end{array}$ & $\begin{array}{l}\text { 1,14: eu sou um } \\
\text { grande rei }\end{array}$ \\
\hline
\end{tabular}

Outros autores também defendem a hipótese de que o sentido real do v.11 só pode ser apreendido quando lido em conexão com o v. 14b. O sentido da disputa seria apresentar YHWH como um grande rei por toda a extensão do orbe. O seu culto não está sendo realizado de forma própria em Jerusalém por negligência dos sacerdotes. Este estado de coisas não pode continuar. Por isso, a manifestação de YHWH no v. 10, afirmando que as portas do santuário deveriam ser fechadas, para que não se acendesse o altar inutilmente, uma vez

\footnotetext{
${ }^{23}$ Cf. WILli-PLEIN, I. Haggai, Sacharja, Maleachi. pp. 251-252; cf. também nota 178.

${ }^{24}$ Cf. WILLI-PLEIN, I. Haggai, Sacharja, Maleachi. pp. 254-255. Na página 255 a autora afirma: "Gott der Vater, die Heiligung seines Namens, seine Königsherrschaft über die ganze Welt."
} 
que, sendo oferecido de maneira negligente, o culto não atrairá a bênção de YHWH, mas, sim, sua maldição (cf. 1,14a). ${ }^{25}$

Um dado arqueológico interessante a ser notado aqui são os baixos-relevos do palácio de Persépolis que mostram como eram as audiências com o rei da Pérsia. São vislumbradas grandes procissões onde são oferecidos dons e aquele que se aproxima do grande rei deve colocar a mão na boca, para não incomodá-lo com seu "mau hálito". ${ }^{26}$ Para Willi-Plein este último costume parece estar ligado à crítica de Ml 1,13c, onde com o verbo נפח YHWH repreende os sacerdotes que "sopram" demonstrando desprezo para com o culto. YHWH seria então o "grande Rei" a quem se devem homenagens como ao grande rei da Pérsia. ${ }^{27}$

Embora a imagem por trás do oráculo possa refletir algo da experiência da cultura persa, seja na própria residência do imperador ou, quem sabe mais provavelmente, na residência do seu imagem de YHWH como rei é anterior ao exílio.

É possível que títulos reais tenham sido atribuídos a YHWH em períodos muito antigos, todavia, parece verossímil afirmar que a concepção da realeza de YHWH só alcançou relevância teológica quando se implantou o culto oficial em Jerusalém. ${ }^{28}$ De fato, a instauração da monarquia e a construção de um santuário nacional erigido pelo rei incidiram de maneira contundente sobre a religiosidade israelita. ${ }^{29} \mathrm{~A}$ própria instauração da monarquia davídica foi interpretada em relação com a realeza de YHWH e seu domínio universal. ${ }^{30}$ Parece ter sido, todavia, um desenvolvimento próprio da teologia jerosolimitana a concepção de YHWH como rei não só de Israel, mas de todas as nações (cf. Sl 47,9). Parece ter sido a experiência das vitórias do povo contra seus inimigos que levou a essa concepção propriamente jerosolimitana do reinado de YHWH sobre os povos. ${ }^{31}$

${ }^{25}$ Cf. MEINHOLD, A. Maleachi. p. 133.

${ }^{26}$ Cf. KESSLER, R. Maleachi. pp. 144-145; WILLI-PLEIN, I. Haggai, Sacharja, Maleachi. pp. 243-253.

${ }^{27}$ Cf. WILli-PleIN, I. Haggai, Sacharja, Maleachi. pp. 242: "Gott is also der eigentliche 'Großkönig', dem Ehrfurcht, Huldigung und Tribut zu zollen sind, wie es gegenüber dem persischen Großkönig geschieht."

${ }^{28} \mathrm{Cf}$. ALBERTZ, R. Historia de la religión de Israel em tiempos del Antiguo Testamento. V. 1. Madrid. Editorial Trotta. 1999. p. 242.

${ }^{29}$ Cf. ALBERTZ, R. Historia de la religión de Israel em tiempos del Antiguo Testamento. p. 231.

${ }^{30}$ Cf. ALBERTZ, R. Historia de la religión de Israel em tiempos del Antiguo Testamento. p. 219.

${ }^{31}$ Cf. ALBERTZ, R. Historia de la religión de Israel em tiempos del Antiguo Testamento. pp. 
A imagem de YHWH como Rei é muito atestada nos salmos. Particularmente, nos Salmos 47, 95 e 96 a metáfora é recorrente. No Salmo 47 YHWH

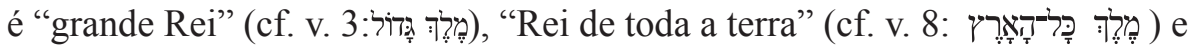

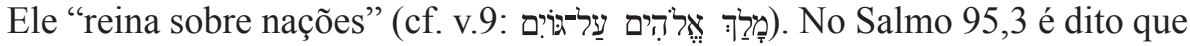

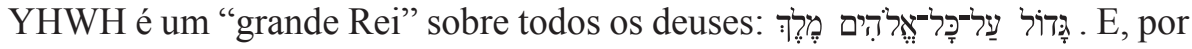

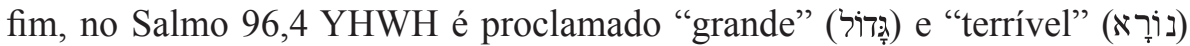
sobre todos os deuses. Do ponto de vista da fraseologia, Weyde faz notar que na BH a expressão Ml 1,14; S1 47,3; 95,3; Ecl 9,14. Referindo-se a YHWH a expressão encontra-se somente nas três primeiras passagens assinaladas. ${ }^{32}$

Do ponto de vista do vocabulário existem muitas semelhanças entre Ml 1,6-14 e os três salmos citados:

\begin{tabular}{|c|c|c|}
\hline S1 47,3: מֶלֶּ גָגדוֹל & um grande rei & Cf. Ml 1,14d \\
\hline S1 47, 9: & povos & Cf. Ml 1,11b.11e.14f \\
\hline אֵל גָדוֹל :S1 95,3 & um grande Deus & Cf. Ml 1,9a \\
\hline 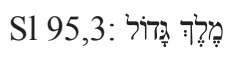 & um grande rei & Cf. Ml 1,14d \\
\hline S1 96,4: & grande & Cf. Ml 1,11b.11e.14d \\
\hline S1 96,4: נוֹרָא & terrivel & Cf. Ml 1,14f \\
\hline
\end{tabular}

O Salmo 47,9 fala do "reinado" de YHWH sobre todos os povos, enquanto que Ml 1,11b.11e.14f supõe o reinado de YHWH e o "temor" que Ele recebe também de todos os povos. Neste último aspecto, Ml 1,14f se alinha com o S1 96,4. O mesmo S1 96,4 proclama a grandeza de YHWH sobre todos os deuses enquanto que Ml 1,11a.c proclama a grande do "nome" de YHWH, mas entre as nações, sem fazer referência aos seus deuses. Dahood chama a atenção

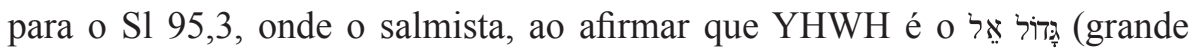
Deus), está, de certa forma, contrapondo YHWH com a divindade El, chefe do

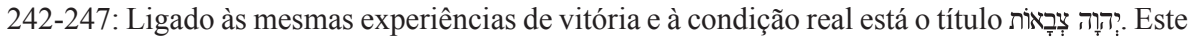
aparece como vinculado à arca da Aliança (cf. 1Sm 4,4; $2 \mathrm{Sm} 6,2$ ) e, segundo alguns autores, é provável que tenha sua origem no santuário de Silo. Alguns chegam mesmo a afirmar que

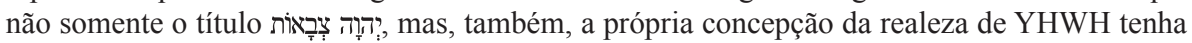
origem nesse santuário.

${ }^{32}$ Cf. WEYDE, K. W. Prophecy and Teaching. Berlin, New York: Walter de Gruyter. 2000. pp. 157-158. 
panteão cananeu. ${ }^{33}$ Malaquias utiliza uma grande quantidade de epítetos para YHWH e, entre estes, aparece também em 1,9a o epíteto אל quando o profeta convida, de forma irônica, os sacerdotes a aplacar a "face de Deus" (פְּני־אלי).

O conjunto dessas afirmações aponta para a possibilidade de a imagem de YHWH como Rei ser uma chave de leitura de Ml 1,6-14. A origem da teologia de YHWH como Rei, conforme visto acima, é cultual. O Sitz im Leben de Ml 1,6-14 é, também, apontado por alguns autores, como sendo o culto. ${ }^{34}$ Malaquias teria lançado mão de uma imagem conhecida dos sacerdotes e, também do povo, para tornar ainda mais pesado o seu juízo sobre os mesmos sacerdotes. Segundo Mason, como YHWH é rei de toda a terra (cf. S1 47,8), quando os homens louvam o criador, eles estão, na verdade, ainda que sem saber, cultuando a YHWH com mais sinceridade que os sacerdotes que, conhecendo o seu "nome", ministram sem zelo e de forma negligente..$^{35}$ Utilizando uma imagem conhecida dos israelitas - sacerdotes e povo - a saber, a imagem de YHWH como Rei, Malaquias chama a atenção de todos a perceberem como é errôneo oferecer a YHWH dons que não são dignos nem de um simples governador (Ml 1,8c), quanto mais d'Aquele que é rei sobre a terra inteira.

\section{Considerações finais}

A recorrência do vocábulo שִ (nome) e o encerramento do texto com a auto-proclamação de YHWH como grande rei, fez com que esta comunicação aprofundasse a relação de Ml 1,6-14 com a teologia do "nome de YHWH" e com a imagem de YHWH como rei, presente sobretudo nos salmos e, aparentemente, de origem cultual. Parece, então, verossímil afirmar que houve influência deuteronomista na composição da profecia, sobretudo a partir de Dt 12 que fala da importância do Templo como habitação do "nome de YHWH" e que Malaquias tem por trás de sua profecia, especificamente de 1,6-14, a imagem de YHWH como um grande rei, cuja morada é o Templo, lugar perpétuo do seu "nome" que está sendo profanado por meio de vítimas impuras.

\footnotetext{
${ }^{33}$ Cf. DAHOOD, M. Psalms 51-100. Garden City, New York. Doubleday \& Company, Inc. 1973. p.353.

${ }^{34}$ Cf. WILLI-PLEIN, I. Haggai, Sacharja, Maleachi. pp. 246; McCOMISKEY, T. E. The Minor Prophets. Grand Rapids, MI: Baker Academy.1992. p. 1296.

${ }^{35}$ Cf. MASON, R. The Books of Haggai, Zechariah and Malachi. pp. 142-145.
} 


\section{Referências bibliográficas}

ACHTEMEIER, E. Nahum-Malachi. Kentucky, Louisville: John Knox Press. 1986.

ALBERTZ, R. Historia de la religión de Israel em tiempos del Antiguo Testamento. V. 1. Madrid: Editorial Trotta. 1999.

CATHCART, K. J.; GORDON, R. P. The Targum of the Minor Prophets. Collegeville, Minnesota: Liturgical Press. 1990.

CHARY, T. Aggée-Zacharie-Malachie. Paris: Gabalda. 1969.

CRAIGIE, P. The Book of Deuteronomy. Grand Rapids, Michigan: Eerdmans Publishing. 1976.

DAHOOD, M. Psalms 51-100. Garden City, New York: Doubleday \& Company, Inc. 1973.

DENTAN, R. C. The Book of Malachi. In: BUTRICK, G. A. (ed.). The Interpreter's Bible. V. 6. New York, Nashville: Abingdon Press. 19511957. pp. 1124-1131.

DIDACHÉ. In: Padres Apostólicos. São Paulo: Paulus. 1995. pp. 357-358.

FLOYD, M. H. Minor Prophets Part 2. Grand Rapids, Michigan: Eerdmans. 2000.

GESENIUS, W.; KAUTZSCH, E. Gesenius' Hebrew Grammar. Oxford: Clarendon Press. 1910.

GLAZIER-McDONALD, B. Malachi: The Divine Messenger. Atlanta, Georgia: Scholars Press. 1987.

IRENEU DE LIÃO. Adversus Haereses. São Paulo: Paulus. $1995^{2}$.

JUSTINO. Diálogo com Trifão. São Paulo: Paulus. 1995. pp. 287-289.

KESSLER, R. Maleachi. Freiburg im Breisgrau: Verlag Herder. 2011.

LESCOW, T. Das Buch Maleachi. Stuttgart: Calwer Verlag. 1993.

LINDBLOM, J. Prophecy in Ancient Israel. Oxford: Blackwell. 1962.

MASON, R. The Books of Haggai, Zechariah and Malachi. London, New York, Melbourne: Cambridge University Press. 1977.

McCOMISKEY, T.E. The Minor Prophets: An Exegetical and Expository Commentary. Grand Rapids. MI: Baker Academic. 1992. 
MEINHOLD, A. Maleachi. Düsseldorf. Neukirchener Verlag. 2006.

STÄHLI, H. P. ירא. In: JENNI, E.; WESTERMANN, C. (ed.). Diccionario Teologico Manual del Antiguo Testamento. Madrid: Ediciones Cristiandad. 1978. V. I. pp. 1051-1068.

STEVENSON, K. Liturgy, Use of the Bible in. In: COGGINS, R. J. et HOULDEN, J. L. A Dictionary of Biblical Interpretation. London: SCM Press. 1990. pp. 405-406.

SWETNAM, J. Malachi 1,11: An Interpretation. Catholic Biblical Quaterly. n. 31. 1969. pp. 200-209.

VERHOEF, P.A. The Books of Haggai and Malachi. Grand Rapids, MI: Eerdmans. 1987.

VIBERG, Å. Wakening a Sleeping Metaphor: A New Interpretation of Malachi 1:11. Tyndale Bulletin. November 1, 1994. 45(2). pp. 297-319.

VRIEZEN, T. C. How to Understand Malachi 1:11. In: COOK, J. (ed.) Grace Upon Grace. Essays in Honor of Lester J. Kuyper. Grand Rapids, Michigan. Eerdmans Publishing Company. pp. 128-136.

WEINFELD, M. Deuteronomy and the Deuteronomic School. Winona Lake, Indiana: Eisenbrauns. 1992.

WEYDE, K. W. Prophecy and Teaching. Berlin; New York: Walter de Gruyter. 2000 .

WILLI-PLEIN, I. Haggai, Sacharja, Maleachi. Zürich: TVZ. 2007.

Fabio da Silveira Siqueira Mestre em Teologia Bíblica pela PUC/RJ Rio de Janeiro/RJ - Brasil E-mail: fabius_siqueira@yahoo.com.br

Recebido em: 01/06/13

Aprovado em: 14/10/13 